\title{
Apresentação dossiê: Gênero e Trabalho: desigualdades reconfiguradas
}

Thays Almeida Monticelli ${ }^{1}$

Podemos dizer que o mundo do trabalho foi - e ainda é - uma das áreas mais enfaticamente analisadas pelas Ciências Humanas no Brasil. Compreender suas dimensões, configurações, reconfigurações, processos e dinâmicas em contextos onde a exploração e dominação estavam sempre materialmente presentes foram os desafios de muitos pesquisadores e pesquisadoras no país. De fato, as relações trabalhistas envolvem aspectos econômicos, sociais, políticos que mobilizam uma gama de sujeitos com diversos interesses em nossa sociedade, sendo assim uma das grandes chaves para entender e abranger as nossas percepções sobre os movimentos sociais que se formam.

O Dossiê "Gênero e Trabalho: Desigualdades Reconfiguradas" vêm justamente reafirmando uma tradição de estudos e pesquisas, que tem como principal foco apontar e analisar os espaços onde os processos de igualdade são invisíveis ou até mesmo inexistentes. Se por um lado podemos ver verdadeiros avanços nos diálogos e na legislação trabalhista para muitos trabalhadores e trabalhadoras, por outro ainda

\footnotetext{
${ }^{1}$ Doutoranda no Programa de Pós Graduação em Sociologia na Universidade Federal do Paraná - UFPR. Mestre em Sociologia também pela Universidade Federal do Paraná. É formada em licenciatura e bacharelado em Ciências Sociais - área Antropologia - pela Universidade Federal de Juiz de Fora - UFJF.
} 
percebe-se uma contínua exploração centrada na interseccionalidade de gênero, raça e classe. Essa realidade pode ser visualizada ao nos depararmos com o resultado da pesquisa realizada pela consultoria "Ernest\&Young" (EY) esse ano, apontando que se o mundo do trabalho continuar mantendo as mesmas tendências corporativas as mulheres levarão oitenta anos para ocupar cargos de chefia em grandes empresas. A diferença em posições trabalhistas não é a única, os homens ainda ganham 30\% a mais que as mulheres ocupando os mesmos cargos trabalhistas e as mulheres negras ganham $25 \%$ menos que as mulheres brancas no Brasil, de acordo com a pesquisa divulgada em 2015 pelo BID (Banco Interamericano de Desenvolvimento).

Assim seguimos compreendo que as desigualdades perpetuadas no mundo trabalho e as suas dificuldades de superação ainda são muito legítimas na sociedade brasileira, exigindo novas possibilidades interpretativas e analíticas. Nessas novas pesquisas surge também a necessidade de evidenciar os processos políticos de emancipação, a formação de novos movimentos sociais e uma percepção crítica dos reais avanços conquistados. O leitor que se deparar com o Dossiê, terá em mãos todas essas questões abordadas nos oito artigos publicados.

O primeiro deles "A Inserção Feminina na Política: Uma Análise da Primeira Edição do "Boletim da Federação Brasileira pelo Progresso Feminino" de autoria de Aline Isabel Waszak, traz o esforço e as estratégias políticas e literárias de mulheres que se empenhavam pelo sufrágio feminino no Brasil, as suas ideologias e a crítica 
direcionada ao papel que a mulher desempenhava na política no contexto do início do século XX.

O segundo artigo intitulado "Configuração de Monteiro Lobato na Crítica à Anita Malfatti (1930)", de autoria de Paula Marinelli Martins nos traz justamente a dimensão dos choques e embates políticos no mundo da arte, que não deixa de fazer parte e refletir diretamente no mundo do trabalho. Para, além disso, seu artigo traz o contexto da construção intelectual política brasileira e as consequências que essas ideologias trouxeram na obra e na vida de Malfatti. A crítica de Monteiro Lobato não só dificultou a sua posição dentro das artes no país, como representava um pensamento retrogrado sobre diversas posições sociais do período.

Saindo do contexto histórico do início do século XX e de posições de mulheres no mundo das artes, da política e do início de uma construção reivindicatórias por direitos, entramos nos artigos que trazem questões relacionadas às desigualdades de gênero perpetuadas no mundo do trabalho de um Brasil mais contemporâneo.

O artigo de Sandro Pereira Silva e André Gambier Campos "Sindicalismo e Gênero no Brasil: A Dinâmica Recente" já nos aponta as complexas relações entre o mundo do trabalho, sindicalismo e gênero. $\mathrm{O}$ artigo analisa o crescimento expressivo de mulheres que se sindicalizaram na década 2000, mas contrapõe esse número ao encontrar grandes dificuldades de adesão de suas pautas no meio 
sindical, que de acordo com os autores, reflete as dificuldades das mulheres no mundo do trabalho.

Já o quarto artigo "Transformações no mundo do trabalho: $\mathrm{O}$ Perfil do Emprego Doméstico nos anos 90 e 2000" de Juliane da Costa Furno e Natasha da Silva Pergher, faz uma análise comparativa entre os anos do governo Fernando Henrique Cardoso e Lula sobre os avanços e retrocessos para as trabalhadoras domésticas no Brasil, compreendo a desigualdade estrutural que essa profissão sustenta e os processos de emancipação política.

O artigo de autoria de Gabriella Ane Dresch, Lincoln Renato Vieira Zanardine e Stéphanie Faux traz uma bela contribuição ao analisar as trabalhadoras de limpeza de uma Universidade Pública no Brasil, destacando não só as desigualdades de gênero e classe, mas também a dupla jornada de trabalho que essas mulheres enfrentam cotidianamente e o estigma social que muitas sofrem por estar nessa posição trabalhista. Além disso, questão como a terceirização são tratados com rigor pelos autores.

A etnografia desenvolvida no artigo "As Mulheres na Construção Civil: Algumas Notas a Partir de um Trabalho de Campo" de Daniela Romcy e Jurema Brites nos apontam com detalhes as dinâmicas e os processos de desigualdades vividos cotidianamente por mulheres em um canteiro de obras, suas dificuldades de serem ouvidas e suas ordens devidamente legitimadas, além das complexas redes que envolvem o mundo público e familiar para as engenheiras. 
O sétimo artigo "Alguns Apontamentos sobre as Mudanças nas Relações de Gênero no Meio Pentecostal" de Otávio Barduzzi Rodrigues da Costa, nos traz uma análise das mudanças em relação a rituais, teologias, costumes que as Assembléias de Deus vem estabelecendo em seus cultos e dinâmicas religiosas, principalmente em relação às mulheres.

E o último artigo do Dossiê, de "Gênero e Sexualidade nas Aulas de Sociologia: Um Olhar sobre a Percepção Discente" de Stephanie Natalie Burille nos apresenta uma realidade educacional que não desenvolve um potencial crítico sobre as questões de gênero em Cuiabá. Sua análise traça a importância da inserção desse tema nas aulas de sociologia, por uma educação não sexista que traz como consequência a reprodução das desigualdades no mundo do trabalho.

O Dossiê aberto pela Revista Vernáculo nos possibilita compreender o Brasil e o mundo do trabalho por meio de perspectivas históricas, dados estatísticos, etnografias, entrevistas, análises do meio político, religioso e educacional. Essas inúmeras interpretações nos abrem cada vez mais espaço para perceber as configurações e reconfigurações das desigualdades de gênero nas relações de trabalho, mas para além disso, nos inspira em construir bases para sanar essas desigualdades e nos remetem a realidades, narrativas e histórias de lutas que nos guiam para novas perspectivas empíricas e analíticas. 